\title{
Palaeontology
}

Regktered Charity No 27636

\section{Rapid transformation in the braincase of sauropod dinosaurs: integrated evolution of the braincase and neck in early sauropods?}

\begin{tabular}{|r|l|}
\hline Journal: & Palaeontology \\
\hline Manuscript ID & PALA-07-17-4031-OA.R1 \\
\hline Manuscript Type: & Original Article \\
\hline Date Submitted by the Author: & 03-Nov-2017 \\
\hline Complete List of Authors: & $\begin{array}{l}\text { Bronzati, Mario; Ludwig-Maximilians-Universitat Munchen Fakultat fur } \\
\text { Geowissenschaften, ; Bayerische Staatssammlung fur Palaontologie und } \\
\text { Geologie, } \\
\text { Benson, Roger; University of Oxford, Department of Earth Sciences } \\
\text { Rauhut, Oliver; Bayerische Staatssammlung für Paläontologie und } \\
\text { Geologie, }\end{array}$ \\
\hline Key words: & \begin{tabular}{l} 
Phylogeny, Rates of evolution, Sauropodomorph, Morphological disparity \\
\hline
\end{tabular} \\
\hline
\end{tabular}




\title{
Rapid transformation in the braincase of sauropod dinosaurs: integrated evolution of the braincase and neck in early sauropods?
}

\author{
Mario Bronzati ${ }^{1,2, *}$, Roger B. J. Benson ${ }^{3, *}$, Oliver W. M. Rauhut ${ }^{1,2}$ \\ ${ }^{1}$ Bayerische Staatssammlung für Paläontologie und Geologie, Richard-Wagner- \\ Straße 10, 80333 Munich, Germany. \\ ${ }^{2}$ Ludwig-Maximilians-Universität, Richard-Wagner-Straße 10, 80333 Munich, \\ Germany. \\ ${ }^{3}$ University of Oxford, Department of Earth Sciences, South Parks Road, OX1 3AN, \\ Oxford, United Kingdom.
}

*Corresponding Authors: mariobronzati@gmail.com; roger.benson@earth.ox.ac.uk

\begin{abstract}
Summary
Sauropod dinosaurs were quadrupedal herbivores with a highly specialised body plan that attained the largest masses of any terrestrial vertebrates. Recent discoveries have shown that key traits associated with sauropod gigantism appeared stepwise during the Late Triassic and Early Jurassic in evolutionary 'cascades' of associated changes, in which a 'head and neck' cascade has been suggested as an important module. Here, we investigate the evolutionary transformation of the sauropodomorph braincase, using discrete anatomical characters, prompted by the reanalysis of a Middle Jurassic (Bathonian) sauropodiform braincase from England. Our analysis shows that sauropod braincases are highly distinct, and occupy a different region of morphospace than their evolutionary relatives. This resulted from anatomical transformations
\end{abstract}


including a set of changes in the surface attachments of craniocervical musculature, which may indicate integrated evolution between neck elongation and transformation in braincase anatomy. Neck elongation in Late Triassic and Early/Middle Jurassic taxa is potentially associated with episodes of skull reduction, indicating that the 'head and neck' cascade was activated more than once in the evolutionary history of Sauropodomorpha. The re-activation of this cascade in the Jurassic may have impacted on the differential survival of sauropodomorph lineages through the EarlyMiddle Jurassic.

\section{Main Text}

Sauropodomorphs are one of the three main dinosaur clades that likely originated by the Early/Middle Triassic (Lloyd et al. 2016), although their oldest definite fossils are from Late Triassic (Carnian - c. $230 \mathrm{Ma}$ ) rocks of South America (Langer et al. 2010; but see Baron et al. 2017). Sauropodomorpha includes Sauropoda, which originated in the Late Triassic (c. $210 \mathrm{Ma}$ ) or Early Jurassic (c. $180 \mathrm{Ma}$ ), depending on the definition adopted for the clade (see below), and survived until the Cretaceous/Paleogene (c. $66 \mathrm{Ma}$ ) mass extinction (Mannion et al. 2011). Sauropods were quadrupedal herbivores that exhibit a characteristic body plan (Upchurch et al. 2004; Sander et al. 2011; Bates et al. 2016) with an elongated neck and tail in combination with a reduced skull and typically gigantic size of up to c. $30 \mathrm{~m}$ in length and at least 70 tonnes in weight (Mazetta et al. 2004; Benson et al. 2014, 2017;

Carballido et al. 2017). The neuroanatomy of sauropods also deviates from other dinosaurs, with sauropods exhibiting the lowest encephalization quotients among all dinosaurs (Hopson 1980). Even without the statistical support of modern approaches 
(e. g. Lloyd 2016), it is clear that sauropod anatomy was highly distinct from that of earlier sauropodomorphs: the earliest sauropodomorphs were small (c. $1.5 \mathrm{~m}$ in length and weighing less than $20 \mathrm{~kg}$; Sereno 1999; Benson et al. 2017), probably bipedal and faunivorous/omnivorous (Barrett 2000; Barrett \& Upchurch 2007; Cabreira et al. 2016). Subsequent anatomical transformations occurred across the skeleton in an apparently stepwise fashion, evidenced by the Late Triassic/Early Jurassic fossil record (e.g. Barrett \& Upchurch 2007; Bonnan \& Yates 2007; Upchurch et al. 2007; Yates et al. 2010; Pol et al. 2011; McPhee et al. 2014, 2015; Otero et al. 2015). These structural changes were part of evolutionary cascades (or the correlated progression model of Thomson 1988) that led to the evolution of gigantism, crucial for the evolutionary success of sauropods during the Jurassic and Cretaceous (Barrett \& Upchurch 2007; Sander et al. 2011, Sander 2013). A key question is whether these transformations occurred through the steady accumulation of anatomical changes at rates comparable to 'background' evolution, or whether they evolved rapidly compared to other changes associated to the origin of the sauropod body plan.

Here we explore the evolution of the braincase (including the posterior portion of the skull roof) of Sauropodomorpha. Although vertebrate braincases have sometimes been regarded as anatomically conservative, with more phylogenetic than functional signal (e.g. Gow 1975; Coria \& Currie 2002; though see Gower \& Sennikov 1996; Rauhut 2007), the braincase may in fact be under strong functional constraints as it bears multiple sites for the attachment of craniocervical musculatures (Romer 1956) and houses important soft tissues, such as the brain and the inner ear (Witmer et al. 2003). Our study is prompted by the reanalysis of a Middle Jurassic (Bathonian) braincase from England (hereafter 'Oxford Braincase') based on microCT-scan data. Originally described as belonging to the theropod Megalosaurus 
(Huene 1906), the specimen was later assigned to Sauropoda, and tentatively referred to Cetiosaurus Owen, 1841 (see review in Galton \& Knoll 2006). Anatomical study of the Oxford Braincase alongside the phylogenetic analysis presented here suports an investigation seeking patterns of morphological transformations and their implications for the evolution of gigantism in Sauropodomorpha.

\section{MATERIAL AND METHODS}

(a) Institutional abbreviations

CM - Carnegie Museum of Natural History, Pittsburgh, USA; GPIT - IFGT, Institut für Geowissenschaften, Universtät Tübingen / Institut und Museum für Geologie und Paläontologie der Universität Tübingen, Tübingen, Germany; MCP-PV - Museu de Ciência e Tecnologia da PUC-RS, Porto Alegre, Brazil; NM - National Museum, Bloemfontein, South Africa; OUMNH - Oxford University Museum of Natural History, Oxford, UK; PVSJ - Museo do Ciencias Naturles, Universidad Nacional de San Juan, San Juan, Argentina; Staatliches Museum für Naturkunde, Germany; ZDM - Zigong Dinosaur Museum, Zigong, China.

\section{(b) Systematic terminology}

Here we follow the definitions proposed by Galton \& Upchurch (2004) for Sauropodomorpha (the most inclusive clade containing Saltasaurus but not Passer or Triceratops) and by McPhee et al. (2014) for Sauropodiformes (the most inclusive clade containing Saltasaurus but not Massospondylus). Based on the discussion in Peyre de Fabrègues et al. (2015), we opted to follow the definition of Salgado et al. (1997) for Sauropoda (the least inclusive clade containing Vulcanodon and 
Eusauropoda) instead of any of the alternative definitions for this clade (e.g. Upchurch et al. 2007; Yates 2007a).

(c) Material and virtual preparation of the Oxford Braincase

As reported by Galton \& Knoll (2006), existing information on OUMNH J13596

(Fig. 1), the Oxford Braincase, indicates that it most probably comes from the White Limestone Formation (Procerites hodsoni Ammonite Zone), which is Middle Jurassic (upper Bathonian - c. 168 Ma) in age (Palmer 1979; Wyatt 1997). OUMNH J13596 is a partially preserved braincase consisting of parts of the basioccipital and parabasisphenoid, parietals, laterosphenoids, prootics, supraoccipital and otoccipital. High resolution computed tomography was used to visualise the morphology of the braincase and internal cavities that housed associated soft tissues. The scan was conducted on the Nikon Metrology XT H 225 ST micro-CT scanner at Natural History Museum, London, using $210 \mathrm{kV}$ and 150 micro-amps with a $2 \mathrm{~mm}$ copper filter and capturing in total 3142 projections. The scan resolution (isotropic voxel size) was 99.452 microns. Segmentation was conducted using the software Amira (version 6.0.1, Visage Imaging, Berlin, Germany).

\section{(d) Phylogenetic analysis}

To test the affinities of the Oxford Braincase, we conducted a phylogenetic analysis using a modified version of the data matrix presented in Bronzati \& Rauhut (2017); which consists of an expanded version of the dataset of Yates (2007b) and subsequent studies focusing on non-neosauropodan sauropodomorphs (e.g. McPhee et al. 2014, 2015). Changes in the matrix (see Bronzati et al. 2017a) comprise the addition of four new characters, and also the inclusion of the Oxford Braincase as an operational 
taxonomic unit (OTU). The analysis was conducted in the software TNT (Goloboff et al. 2008) using an heuristic search with the following specifications: 5000 replicates of Wagner Trees, hold 10, TBR (tree bi-section and reconnection) for branch swapping. The most parsimonious trees (MPTs) found in this first analysis were subjected to a second round of TBR.

\section{(e) Discrete character-taxon matrix analysis}

Principal co-ordinates analyses (PCoA) were used to investigate morphospace (=discrete character space) occupation of sauropodomorph braincases, including both non-sauropods and early sauropods. Analysis of rates of discrete character evolution, implemented in the R package Claddis (Lloyd 2016), were also used to quantify rates of evolution of the braincase anatomy of sauropodomorphs. Both analyses use a discrete character-taxon matrix as primary data, and the estimation of evolutionary rates requires a phylogeny with branch lengths as a framework (reviewed by Lloyd 2016). The characters used in these analyses consist only of those related to braincase anatomy (29 out of the 379 in the matrix for the phylogenetic analysis - see Bronzati et al. $2017 \mathrm{a})$.

Our PCoA was conducted using the pairwise matrix of Gower distances for braincase characters between taxa in the matrix (reviewed by Wills et al. 1994; Lloyd 2016). To ameliorate problems of non-comparability, which occur when a pair of taxa have no characters scored other than missing data in common, we screened taxa for inclusion in the PCoA based on the presence of less than 50\% missing data in total. In other words, only taxa with at least $50 \%$ of braincase character scored other than missing data were included in this analysis (27 out of 59 taxa in total). 
Our evolutionary rates analyses were conducted across a subset of 100 MPTs recovered by our phylogenetic analysis, rather than on a single consensus topology. This allowed us to determine the influence of phylogenetic uncertainty on our results. We added five neosauropod taxa from the Middle and Late Jurassic to the matrix in order to avoid the loss of information that would otherwise occur by representing a diverse clade as a single terminal taxon. To achieve this, we replaced the single terminal "Neosauropoda" in our set of MPTs with two alternative topologies of a clade containing five taxa: (1) (Jobaria, ((Camarasaurus supremus, Giraffatitan ), (Tornieria, Dicraeosaurus sattleri))); (2) ((Jobaria, (Camarasaurus supremus, Giraffatitan)), (Tornieria, Dicraeosaurus sattleri)). These two alternative topologies take into account the uncertainty regarding the position of Jobaria (e.g. Sereno et al. 1999; Upchurch et al. 2004; Sander et al. 2011), which is either found within Macronaria (here represented by Camarasaurus supremus and Giraffatitan brancai), or as the sister group of Neosauropoda, which includes Macronaria and Diplodocoidea (the latter represented by Tornieria and Dicraeosaurus).

Trees were time-scaled by enforcing a minimum branch length ('mbl'; Laurin 2004) of 1 Ma using the timePaleoPhy function of the R package paleotree (Bapst 2012). We conducted two sets of analyses, one using the full set of MPTs, allowing a Late Triassic/Early Jurassic split of the Oxford Braincase from other sauropodiforms. This is a very unlikely scenario because it implies hitherto undetected survival of a Triassic-diverging sauropodomorph lineage in the Middle Jurassic. Nevertheless, it cannot be ruled out based on character evidence because of the paucity of Triassic sauropodomorph braincases so far discovered. In the second set of analyses, we constrained the position the Oxford Braincase to belong to Cetiosaurus (the only sauropod identified from the potential source localities in the Bathonian of the UK, 
from which the braincase comes; Galton \& Knoll 2006), and therefore to be nested in the less inclusive clade containing Spinophorosaurus nigerensis and eusauropods. This clade currently includes all Middle Jurassic and younger sauropodomorphs (see also item 'b' of Results section).

Evolutionary rates were estimated using the DiscreteCharacterRate function of the R package Claddis (Lloyd 2016), including only those taxa for which at least 50\% of braincase characters were scored. 'High' or 'low' rates that can be differentiated from the background rates of character state transitions were identified by the occurrence of individual branches that attained p-values of 0.05 or lower using the maximum likelihood test for comparison among rates inferred for internal branches only (systematically low rates of character evolution occur on terminal branches, and their inclusion would bias our analysis towards finding significantly high rates on any given internal branch; Lloyd 2016).

\section{RESULTS}

\section{(a) Osteology and soft tissue anatomy of the Oxford braincase}

The computed tomography data allowed us to produce a detailed virtual model of the braincase and associated cavities representing soft tissue structures (Fig. 1). These include the inner ear, and parts of the hindbrain, including cranial nerves (V-XII) and blood vessels. A more detailed osteological description of the Oxford Braincase has already been provided by Galton \& Knoll (2006), and only specific and novel aspects are discussed here. The parietals are anteroposteriorly short, and in dorsal view the supratemporal region of the skull is longer transversely than anteroposteriorly (Fig. 1). The same configuration is observed for the supratemporal fenestra, with a longer 
transversal axis. In dorsal view, the posterodorsal surface of the skull is horizontally aligned, an aspect given by the transverse orientation of the paroccipital process. This is the typical condition of sauropods, whereas non-sauropodan sauropodomorphs have a paroccipital processes that projects posterolaterally (Galton 1985; Yates 2007b). We recognise no clear indication of a bony bar dividing the foramen in the otoccipital posterior to the fenestra ovalis (= fenestra vestibule; Sampson \& Witmer 1997) and anterior to the hypoglossal nerve, as hypothesized by Galton \& Knoll (2006, figs. $3 \mathrm{c}, \mathrm{d})$. Thus, the aperture is here regarded as the metotic foramen (sensu Gower \& Weber 1998 - see discussion below). The otosphenoidal crest is represented by a low ridge, which has its posterodorsal limit located at the proximal portion of the paroccipital process and the anteroventral limit at the anterodorsal portion of the parabasisphenoid. An otosphenoidal crest formed by a low-ridge is typical of nonsauropodan sauropodomorphs (Bronzati \& Rauhut 2017), whereas some sauropods, especially diplodocoids, exhibit an almost lamina-like crest with a posterolateral projection that obscures part of the fenestra ovalis in lateral view (Janensch 1935; Tschopp et al. 2015).

The positions of the cranial nerves in the Oxford Braincase (Fig. 1) follow the typical pattern observed in sauropods and other dinosaurs (e.g. Witmer et al. 2008; Balanoff et al. 2010; Paulina-Carabajal 2012; Knoll et al. 2012). The foramen associated to the trigeminal nerve (cranial nerve $\mathrm{V}$ ) is located anteroventral to the vestibule (which hosts the semicircular canals of the inner ear). Dorsal to the foramen associated to the trigeminal nerve, an additional foramen corresponds to the ventrolateral exit of the mid-cerebral vein. Sauropods typically exhibit independent foramina for the vein and the trigeminal nerve in this region of the braincase (e.g. Balanoff et al. 2010; Knoll et al. 2012; Paulina-Carabajal 2012). The mid-cerebral 
vein also has a dorsal component that exits the braincase at the level of the occipital plate of the skull (Sampson \& Witmer 2007), but it was only possible to reconstruct its anteroventral path on the lateral surface of the Oxford Braincase endocast (Fig. 1). Low protuberances in both sides of the braincase endocast (Fig. 1), posterior to the point of confluence of the dorsal and ventral rami of the mid-cerebral vein, are identified as the floccular fossae lobe (sensu Ferreira-Cardoso et al. 2017). Brain tissues associated to the floccular fossae lobe likely correspond to the flocculus and paraflocculus of the cerebellum (see Ferreira-Cardoso et al. 2017). As is typical for sauropods (e.g. Witmer et al. 2008; Paulina-Carabajal 2012), these protuberances in the brain endocast of the Oxford Braincase do not project into the space between the reconstructed semi-circular canals of the inner ear. The facial nerve (VII) would have exited the endocranial cavity through a foramen located posterior to the ventral region of the foramen associated to the trigeminal nerve, and ventral to the osteological correlates of the anterior and lateral semi-circular canals of the inner ear in the vestibule. A pair of apertures in the anteroventral portion of the braincase, at approximately the same anteroposterior level of the opening for the facial nerve laterally, corresponds to the foramina through which the abducens nerves (VI) exited the endocranial cavity. The hypoglossal nerve (XII) has two main branches that exit the braincase through separate apertures (Fig. 1). This condition is observed in all non-sauropodan sauropodomorphs, and has also been reported for other sauropods, such as Spinophorosaurus nigerensis (Knoll et al. 2012), Shunosaurus lii (Chatterjee \& Zheng 2002), Nigersaurus taqueti (Sereno et al. 2007), and Diplodocus (Witmer et al. 2008). In contrast, the presence of a single opening for the hypoglossal nerve was reported for neosauropod taxa such as Camarasaurus, the dicraeosaurids Amargasaurus cazaui (Paulina-Carabajal et al. 2014) and most of the titanosaurians 
(Paulina-Carabajal 2012). Additionally, the presence of a third ramus of the hypoglossal has been hypothesized for Apatosaurus (Balanoff et al. 2010). A protuberance on the posterior region of the brain endocast of the Oxford Braincase, dorsal to the hypoglossal nerves, is interpreted as a blind dural venous sinus of the hindbrain, which is topologically equivalent to that reported for the Middle Jurassic neosauropod Spinophorosaurus nigerensis (Knoll et al. 2012).

The anterior semi-circular canal (ASC) of the inner ear of the Oxford Braincase (Fig. 1) has the greatest length of the three semi-circular canals (measurements were taken following a midline between the walls of the the cavities associated to each canal). The lateral semicircular canal (LSC) is the shortest of the three canals, with a length of c. 0,38 of the ASC and 0,44 of the posterior semicircular canal (PSC). With the lateral semi-circular canal aligned horizontally, the crus commune of the inner ear of the Oxford Braincase exhibits a vertical orientation, similar to the condition observed in Massospondylus and Nigersaurus taqueti (Sereno et al. 2007). This condition is slightly different from the one reported for Spinophorosaurus nigerensis, which exhibits a crus commune that is slightly curved posteriorly (Knoll et al. 2012). The lagena of the Oxford Braincase is cone shaped, tapering distally (i.e. ventrally). The length of the lagena (from the ventral limit of the fenestra ovalis till the ventral tip of the lagena) is c. 1.7 times the length of the lateral surface of the vestibule from the ventral limit of the LSC till the dorsal limit of the fenestra ovalis. The diameter of the fenestra ovalis (= oval window of some authors) remains relatively constant around its entire length, and as in Spinophorosaurus (Knoll et al. 2012), it also has an oval outline. Finally, the diameter of the fenestra ovalis is c. 1.8 to 2.0 times the diameter of the fenestra cochleae (= round window of some authors). However, the relative small size of the latter might be an artefact of 
the segmentation because the limits of this structure were not clearly recognisable in the CT Scan data (Bronzati et al. 2017a).

(b) Phylogenetic analysis

In all of the 2210 MPTs, the Oxford Braincase is found to be more closely related to Neosauropoda than to Melanorosaurus readi. Characters that support this placement of the Oxford Braincase are: supratemporal fenestra with a transverse axis longer than the anteroposterior one (character 59), flat occiput in dorsal view (character 78), and the presence of an undivided metotic foramen (character 370). Additional braincase features that are common to all sauropods included in our analysis are: depth of the parietal wing greater than the depth of the foramen magnum (character. 72); a linear parabasisphenoid/basioccipital junction in the ventral surface of the basicranium (character 84); lack of a medial component of the basioccipital basal tubera (character 82); basioccipital relatively longer than the parabasisphenoid (character 368); an undivided metotic foramen (character 370); the absence of an unossified gap between the basioccipital and basisphenoidal component of the basal tubera and ventral ramus of the opisthotic (character 371). Distinct character states might be present in other Late Jurassic and Cretaceous sauropods, which exhibit great variation in the braincase anatomy (e.g. Tschopp et al. 2015) that is not captured by our phylogenetic analysis. Nevertheless, our analysis, which focuses on non-neosauropodan sauropodomorphs, should return accurate results for the placement of the Middle Jurassic Oxford Braincase.

The PCRPrune command of TNT (Goloboff \& Szumik 2015) was used to generate a reduced strict consensus tree depicting the alternative positions of the unstable OTUs (see Bronzati et al. 2017a). The Oxford Braincase is identified as one 
of the unstable OTUs in our analysis (Bronzati et al. 2017a). The different positions occupied by the Oxford Braincase are within the less inclusive clade including Antetonitrus longiceps and Neosauropoda, or as the sister group of this clade. Thus, applying the definition of Salgado et al. (1997) for Sauropoda and the definition of McPhee et al. (2014) for Sauropodiformes in our strict consensus tree (see Bronzati et al. 2017a), the Oxford Braincase is recovered as a non-neosauropodan sauropodiform. It is worth mentioning that using the more inclusive definition of Yates (2007a) for Sauropoda, the Oxford Braincase would correspond to a sauropod in our analysis. In this context, the sauropod condition of the Oxford Braincase, as previously suggested by Galton \& Knoll (2006), relies on the definition adopted for Sauropoda.

Finally, it is worth emphasising one aspect of the multiple alternative positions of the Oxford Braincase recovered by our parsimony analysis. The position of this OTU as the sister group or within the minimal clade defined by node $\mathrm{C}$ (which contains Antetonitrus and Neosauropoda) is supported by a set of morphological characters, as mentioned above. However, alternative positions (see Bronzati et al. 2017a) between nodes C and D (see Fig. 2) occur because all taxa within this paraphyletic array lack braincase material. Therefore, all potential positions of the Oxford Braincase along this grade are equally parsimonious (and so equally supported by character evidence on its own), because all other taxa in this region of the tree are scored with missing data for braincase characters.

\section{(c) Discrete character-taxon matrix analyses}

Our PCoA (Fig. 3) shows that sauropod braincases occupy a different region of morphospace than that occupied by other sauropodomorphs and related sister groups, with no overlap between them. This is evident when plotting PCo 1 (accounting for 
$27.5 \%$ of variation in the braincase character distance matrix) against $\mathrm{PCo} 2$

(accounting for $7.9 \%$ of variation) and $\mathrm{PCo} 3$ (accounting for $5.1 \%$ of variation).

Analyses of rates of character evolution using the full set of MPT's, without

enforcing the position of the Oxford Braincase, return a fast rate of evolution of

discrete characters in 59 out of the 100 trees (see Bronzati et al. 2017a). Of these, 34

(approximately 50\%) found high rates leading to the clade including all Middle

Jurassic and younger sauropods (the minimal clade including Spinophorosaurus and

neosauropods), but excluding the Oxford Braincase. Using the set of MPTs where the

position of the Oxford Braincase was constrained as the one occupied by Cetiosaurus

in the original phylogenetic analysis, a fast rate of evolution in the branch leading to

the Middle Jurassic sauropods is recovered in 91 of the 100 trees (see Bronzati et al.

2017a). The clade in this case corresponds to the minimal clade including

Spinophorosaurus and Neosauropoda.

\section{DISCUSSION}

(a) Braincase anatomy

In their description of the Oxford Braincase, Galton \& Knoll (2006) hypothesized the presence of a bony strut subdividing the foramen here interpreted as the metotic foramen. If the metotic foramen was truly divided, it should imply that the bony strut dividing it was broken on both sides (see Galton \& Knoll 2006). However, the smooth margins of the foramina indicate that the presence of a bony strut is not likely. Additionally, a bony strut is present in non-sauropod sauropodomorphs such as Massospondylus (Gow 1990; Barrett 2009), Melanorosaurus (Yates, 2007b; Nair et al., 2015) and Efraasia minor (Bronzati \& Rauhut 2017), which have braincases that are smaller and less robust than the Oxford Braincase. Thus a breakage on both sides 
of the Oxford specimen seems unlikely, especially because all the bony struts dividing other foramina are preserved on both sides, such as the one between the fenestra ovalis and the metotic foramen. In this context, our interpretation is that the Oxford Braincase has a single foramen for the exit of cranial nerves IX-XI and the posterior cephalic vein, similar to the condition observed in Middle Jurassic sauropods such as Spinophorosaurus (Knoll et al. 2012) and Shunosaurus (Chatterjee \& Zheng 2002). In contrast, non-sauropodan sauropodomorphs, with the exception of Plateosaurus (e.g. Prieto-Marquez \& Norell 2011; but see Galton 1985), exhibit a pair of foramina (Bronzati \& Rauhut 2017).

There are two alternative hypotheses regarding the nature of the pair of foramina discussed above in non-sauropodan sauropodomorphs (Bronzati \& Rauhut 2017). One possibility is that they represent the fenestra pseudorotunda (anterior opening), which is covered by a secondary tympanic membrane, and a vagal foramen (posterior opening) for the passage of the vagus nerve and possibly the posterior cephalic vein (e.g. Sampson \& Witmer 2007; Sobral et al. 2012). An alternative scenario is that there is no division of the metotic foramen and hence the formation of a secondary tympanic membrane (i.e. absence of a fenestra pseudorotunda). In this sense, there is a metotic foramen (anterior opening) and the additional foramen (posterior foramen) is the result of further ossification resulting in a separate opening for the posterior cephalic vein dorsally (Gower 2002). If the latter is true, the presence of a single foramen in sauropods indicates that the posterior cephalic vein simply exited the braincase laterally, together with cranial nerve X; or, that the cephalic vein of sauropods possibly exited the braincase through the foramen magnum as reported for some lepidosaurs (Bellairs \& Kamal 1981), especially because of the small size of the posterodorsal opening (Balanoff et al. 2010; Bronzati \& Rauhut 2017). However, 
if the former is true (i.e. the anterior foramen is homologous to the fenestra pseudorotunda of birds and crocodiles), it indicates that sauropods have secondarily lost their auditory pressure relief window (Clack \& Allin 2004), the fenestra pseudorotunda (Gower \& Weber 1998). Nevertheless, a more detailed investigation on the presence/absence of an additional foramen among taxa of Sauropoda subgroups is necessary before making more definitive inferences regarding the ecological and/or physiological significance of a possible loss of the fenestra pseudorotunda or the change in the path of the posterior cephalic vein.

A relative short LSC (i.e. in relation to ASC and PSC) has been reported for the dicraeosaurid Amargasaurus cazaui (Paulina-Carabajal et al. 2014), the macronarian Giraffatitan brancai (Clarke 2005; Knoll and Schwarz-Wings 2009), and for the tinatosaurians Antarctosaurus wichmannianus and Bonatitan reigi (PaulinaCarabajal 2012). This also seems to be the case for taxa such as the diplodocoid Diplodocus longus (Sereno et al. 2007); although relative measurements were not provided. On the other hand Knoll et al. (2012) reported that all the semicircular canals of Spinophorosaurus are relatively long. However, our interpretation is that the condition of Spinophorosaurus mostly matches the condition observed in the Oxford Braincase, with a LSC with a length corresponding to less than $45 \%$ of the length of the ASC and the PSC. In this case, the condition of the latter two taxa would be similar to the one of the sauropods reported above, with the presence of a LSC that is shorter than the other two semicircular canals. In fact, the presence of a LSC that is shorter than the other two canals is commong among tetrapods (see e.g. Clack et al. 2016), but a further relative reduction of the LSC in relation to the other canals seems to happen among sauropodomorphs. In the Oxford Braincase, the ASC and PSC are c. 2.61 and c. 2.25 longer than the LSC, respectively. This is different from the 
condition of the Late Triassic non-sauropodan sauropodomorphs Saturnalia tupiniquim $(\mathrm{ASC} / \mathrm{LSC}=$ c. $1.54 ; \mathrm{PSC} / \mathrm{LSC}=$ c. 1.20$)$ and Plateosaurus $(\mathrm{ASC} / \mathrm{PSC}=$ c. 1.17; PSC/LSC = c. 1.39), on which neither the ASC nor the PSC are twice as long as the LSC (Bronzati et al. 2017b).

\section{(b) Rates of evolution in the braincase anatomy of sauropodomorphs}

A fast rate of braincase evolution is recovered along the lineage leading to the clade of Middle Jurassic and younger sauropods (node D in Fig. 2) in c. $60 \%$ of the trees when the Oxford Braincase is not constrained in the position of Cetiosaurus (see Bronzati et al. 2017a). For these 60 trees, character state transition frequencies (= rates) are similar to those reported below for constrained trees. This is a moderate indicator of rapid transformation in sauropodomorph braincase anatomy prior to the Middle Jurassic. However, in the unconstrained subset of MPTs, most trees recover the Oxford Braincase either as the sister group of Antetonitrus + Lessemsaurus, the sister-group of the minimal clade including Antetonitrus and Neosauropoda, or the sister-group of the minimal clade including Leonerasaurus and Neosauropoda. As mentioned above, the latter is a very unlikely scenario because this would imply a still undetected survival of a Triassic-diverging sauropodomorph lineage in the Middle Jurassic. Furthermore, in this configuration, optimization of braincase characters at the branch leading to the clade including Middle Jurassic sauropods is more ambiguous because of the high percentage of missing data for the Oxford Braincase. Only six of the 13 characters undergoing transformation in the branches associated with Middle Jurassic sauropods are scored for this taxon.

Conversely, if the Oxford Braincase belongs to Cetiosaurus, a sauropod of which other bones are known from the same locality (Galton \& Knoll 2006), 
character optimization at the branch leading to the clade of the Middle Jurassic sauropods is improved (i.e. fewer states are optimised ambiguously). In this configuration, Spinophorosaurus is the sister taxon of all the other sauropods (i.e. those with more than $50 \%$ of characters of braincase scored in the matrix), and nine of the 13 characters undergoing transformation in the branches associated with Middle Jurassic sauropods are scored for this taxon. In this arrangement, fast rates of braincase character evolution are recovered along the lineage leading to these Middle Jurassic taxa (node D in Fig. 2) in more than $90 \%$ of the trees. In these trees, braincase character state transition frequencies on this lineage range from 0.35 to 0.75 (see Bronzati et al. 2017a). Compared to a 'background' rate of $0.00-0.15$ (this is the range [across 100 phylogenies] of the median rate on internal branches), this implies minimally more than a doubling of the rate of braincase evolution prior to the origin of Middle Jurassic and younger sauropods. Our results therefore indicate that transformations in the braincase anatomy of sauropods resulted from rapid evolution, rather than from transformations within the range of 'background' rates over a long time interval.

\section{(c) Integrated evolution of the neck and braincase in early sauropods?}

The complete shift in braincase morphospace occupation (Fig. 3) indicated out by our PCoA analyses shows that the braincase osteology of sauropods significantly differs from that of their non-sauropodan relatives. Furthermore, the transformations shaping the braincase of Middle Jurassic sauropods occurred at a fast rate when compared to background rates of evolution. Here we demonstrate that these results can be understood as part of major transformations of the craniocervical complex of sauropods, which are related to further neck elongation in the lineage. 
Besides housing the brain and other sensory organs (Romer 1956), the braincase also bears multiple attachment sites for muscles of the masticatory apparatus and of the craniocervical complex (Snively \& Russell 2007; Button et al. 2014, 2016). A series of transformations in braincase anatomy detected by our analysis correspond to changes in the morphology of sites for the anchorage of neck muscles (also see Button et al. 2016 for discussion regarding changes in the attachment surfaces for muscles of the masticatory apparatus), with the majority of them occurring at the branch leading to the minimal clade including Spinophorosaurus and neosauropods (node D). These are: an increase in the depth of the occipital wing of the parietal (attachment surface of $m$. splenius capitis), change in the orientation of the paroccipital process of the otoccipital from a posterolateral to a lateral orientation in dorsal view (attachment surface of $m$. longissimus capitis superficialis), elongated basioccipital (attachment surface of $m$. rectus capitis dorsalis, $m$. rectus capitis ventralis), and, change from a U- or V-shaped to a linear contact of the basioccipital and the parabasisphenoid at the region of the basal tubera (attachment surface of $m$. rectus capitis dorsalis, m. rectus capitis ventralis) nomenclature for the craniocervical musculature as in Snively \& Russell (2007).

Sauropodomorphs possessing these character states belong to the clade delimited by node $\mathrm{D}$ in Figure 2. The origin of this clade is characterised by elevated rate of transformation in braincase anatomy (see item $\mathrm{C}$ of Results section). Those members of this clade that are known from more complete material exhibit proportionally longer necks in relation to their trunks (Table 1). On the other hand, sauropodomorphs outside the clade delimited by node D have proportionally shorter necks, with a trunk that is longer than the neck (Rauhut et al. 2011). In this context, our findings are consistent with a scenario in which the elongation of the neck (i.e. 
presence of a neck longer than the trunk) in sauropods occurred during the origin of the clade delimited by node $\mathrm{D}$, and this not only involved a series of modifications on vertebral morphology, such as pneumatisation and elongation (e.g. Wedel et al. 2000;

Wedel \& Sanders 2002; Wedel 2005, 2007), but was also accompanied by modifications in the anchor points of neck muscles to the braincase.

Support for this hypothesis is complicated because of difficulties constraining the precise timing of transformations of the sauropod braincase due to the paucity of these elements in the fossil record. The lack of even partially complete specimens, and the total absence of braincases and axial series, is the case for all taxa between nodes C and D (see e.g. Pol \& Powell 2007; Pol et al. 2011; McPhee et al. 2014, 2015). Nevertheless, our observations so far are an indicative of an integrated evolution of the elongated neck with transformation of the braincase in early sauropods; but it is not yet possible to determine the directionality of the causal relation between changes to these anatomical compartments (elongation of the neck $<->$ modification in the region of neck musculature attachment in the braincase).

\section{(d) Multiple activations of the 'head and neck' cascade of gigantism}

Sauropod gigantism is related to a series of evolutionary cascades leading to an increase in body size; among them is the so-called "head and neck" cascade (Sander 2013). As neck length is biomechanically constrained by skull size, the reduction of the skull among Late Triassic sauropodomorphs has been considered as having reduced the moment of force exerted by the head on the neck (Rauhut et al. 2011). Indeed, the reduction of the skull (cranial length $<2 / 3$ of femoral length) occurs at the branch leading to the minimal clade including Saturnalia tupiniquim and neosauropods, suggesting that this transformation took place in the Carnian (Late 
Triassic - c. $230 \mathrm{Ma}$; Langer et al. 2010). The neck length of S. tupiniquim, with a cranial/femoral length ratio of c. 0.64 (estimate), accounts for c. $0.55-0.60$ of the trunk length (Table 1). This represents just a slight elongation in the neck when compared with the possible sauropodomorph Eoraptor lunensis (estimated neck length/trunk length - c. 0.50-0.55) also from the Carnian (Sereno et al. 2012), which does not exhibit a reduced skull (cranial length/femoral length - c. 0.80). However, a more marked cervical elongation (neck/trunk length ratio $>0,7$ ) is recovered at the branch leading to the minimal clade including Plateosaurus and sauropods (node B). For instance, the Norian (c. $215 \mathrm{Ma}$ ) taxon Plateosaurus, with a cranial/femoral length ratio of c. 0.57 , has a trunk/neck ratio of c. 0.75 (Rauhut et al. 2011). This increase in neck length is an indicator that the reduction of the skull in the Carnian triggered the "head and neck" cascade for the first time in Sauropodomorpha evolution (Rauhut et al. 2011). An increase in body-mass is also observed in the minimal clade including Plateosaurus and sauropods. Carnian representatives such as Saturnalia and Eoraptor are small and with a body mass not exceeding $20 \mathrm{~kg}$ (Benson et al. 2014). On the other hand, Plateosaurus attained body masses of c. $910 \mathrm{~kg}$ (Benson et al. 2014), at least one order of magnitude bigger than its older counterparts. Yet, estimates for other non-sauropodan sauropodomorph indicate that these animals could attain body masses up to c. $2300 \mathrm{~kg}$, as is the case of Lufengosaurus (Benson et al. 2014).

In spite of the neck elongation in the Late Triassic, the Middle Jurassic sauropods of the clade delimited by node D have necks that are proportionally much longer than those of other sauropodomorphs (Table 1). Patterns of morphological transformation in the skull of sauropodomorphs are congruent with a further activation of the "head and neck" cascade in the Jurassic, but this time encompassing only sauropods (node D in Fig. 2). The Middle Jurassic taxa Shunosaurus and 
Mamenchisaurus, the only non-neosauropodan sauropods with complete skulls preserved, have a cranial/femoral length ratio of 0,43 (Ouyang \& Ye 2002; Rauhut et al. 2011), and 0,35 (Zhang 1988; Rauhut et al. 2011), respectively (see Table 1). Furthermore, whereas Shunosaurus and Mamenchisaurus already exhibit necks longer than the trunks, all the other sauropodomorphs outside the clade delimited by node D known from more complete materials exhibit the inverse relation (Table 1). Increases in body mass predicted in the "head and neck" cascade are also observed. Body mass of the non-neosauropodan sauropods Shunosaurus are estimated in c. $6300 \mathrm{~kg}$ and those for different species of Mamenchisaurus range from c. $6200 \mathrm{~kg}$ to c. $18000 \mathrm{~kg}$ (Benson et al. 2014). These values are greater than the maximal value of body mass estimated for a sauropodomorph outside the clade delimited by node D, c. $5600 \mathrm{~kg}$ for Antetonitrus (Benson et al. 2014). Yet, even if body mass inferior to the ones of Antetonitrus are estimated for taxa within clade D (e.g. neosauropods such as Amargasaurus and Europasaurus), the biggest mass values estimated among sauropods are for those with a neck longer than the trunk, such as Brachiosaurus and Argentinosaurus (see Benson et al. 2014 for body mass estimates). This can be understood in a scenario that that longer necks diminishes energy consumption during food intake (Martin 1987), allowing animals to attain a greater body mass (Barrett \& Upchurch 2007; Upchurch et al. 2007; Sander 2013).

Support for the hypothesis of a re-activation of the "head and neck" cascade in the Jurassic is also complicated because of difficulties constraining the precise timing of transformations of the sauropod skull. In our phylogenetic hypothesis (Fig. 2), further reduction in cranial length (to less than half of the femoral length) is detected at the branch leading to the minimal clade leading to Shunosaurus and Neosauropoda. However, the shift in braincase anatomy and the fast rate of evolution is detected in 
the branch leading to node D, which includes Spinophorosaurus, for which the total length of the skull cannot be determined. One possibility is that a change in the orientation of the longest axis of the supratemporal fenestra from a parasagittal to transverse plane (character 59), detected at the branch leading to the clade delimited by node D (including Spinophorosaurus), could indicate a reduction in skull length for Spinophorosaurus. Nevertheless, as already mentioned by Sander (2013), other factors such as the presence of light cranial bones (Upchurch et al. 2004) also contributed to minimize the moments of force directed to the neck (Witzel \& Preuschoft 2005), and likely played a role in re-activating the head and neck cascade. More complete materials and/or new specimens of taxa occupying a phylogenetic position between nodes C and D (Fig. 2) will certainly bring important information to test the hypotheses proposed here.

\section{CONCLUSIONS}

New information on the Oxford Braincase helps trace transformations in the sauropod braincase and endocast in more detail, especially concerning the origins of Neosauropoda. Regarding soft tissues, our data indicate an accentuated reduction of the LSC for the Oxford Braincase. However, in the lack of more detailed measurements for other sauropod taxa, it is still not possible to draw a more detailed scenario concerning the evolution of the LSC in the group, as for instance, if the presence of a LSC with a length corresponding to less than half of the length of the ASC and PSC (i.e. the condition observed in the Oxford Braincase) indeed corresponds to the ancestral condition of Neosauropoda. Regarding osteology, our analyses indicate that a first pulse of neck elongation occurring in the Norian (branch 
leading to node B) was preceded by relative skull reduction in the Carnian (branch leading to node A), as also previously reported by Rauhut et al. (2011). However, no significant shift in braincase anatomy could be detected at this point. On the other hand, our data indicates an abrupt evolutionary shift (Figs. 2 and 3) in braincase anatomy that happened concomitantly with neck elongation (i.e. necks longer than the trunks), at the branch leading to the clade delimited by node D (Fig. 2). However, given the data for the braincase and axial series of the taxa within the array between nodes $\mathrm{C}$ and $\mathrm{D}$ (Fig. 2) so far available, it is not possible to determine the directionality of the causal relation between changes in these anatomical compartments.

The moments of neck elongation in sauropodomorph evolutionary history (possibly related to activations of the 'head and neck' cascade) are demonstrated to be related to episodes of skull reduction (Fig. 2) and increases in body mass, which could indicate that the 'head and neck' cascade (Sander 2013) was activated more than once during the evolution of Sauropodomorpha. As greater body mass increases the amount of energy obtained in the context of a fully herbivorous diet and provide more protection against predators (Sander 2013), independent activations of each of the multiple cascades of gigantism might potentially explain the difference in survival among sauropodomorph lineages during the history of the group, such as the disappearance of the non-sauropodan lineages towards the end of the Early Jurassic.

\title{
Acknowledgements
}

\author{
A. A. S. da Rosa, D. Schwarz, D. Abelin, G. Cisterna, H. Ketchum, J. Powell, J. \\ Choniere, P. Barrett, R. Schoch, R. Martinez, S. Chapman, Z. Erasmus helped and/or \\ provided the access to materials in collections, which we are thankful for. We are also
}


thankful to those that contributed by sharing data used in this study: D. Schwarz, B. McPhee, D. Pol, J. Nair, J. Bittencourt, K. Chapelle, E. Tschopp. TNT is a free program made available by the Willi Hennig Society.

\section{References}

BALANOFF, A. M., BEVER, G. S. and IKEJIRI T. 2010. The braincase of Apatosaurus (Dinosauria: Sauropoda) based on computed tomography of a new specimen with comments on variation and evolution in Sauropod Neuroanatomy. American Museum Novitates, 3677, 1-29.

BAPST, D. W. 2012. paleotree: an R package for paleontological and phylogenetic analyses of evolution. Methods in Ecology \& Evolution, 3, 803-807.

BARON, M. G., NORMAN, D. B. and BARRETT, P. M. 2017. A new hypothesis of dinosaur relationships and early dinosaur evolution. Nature, 543, 501-506.

BARRETT, P. M. 2000. Prosauropods and iguanas: speculation on the diets of extinct Reptiles. 42-78. In Sues, -H. D. (ed). Evolution of Herbivory in Terrestrial Vertebrates: Perspectives from the Fossil Record. Cambridge University Press, Cambridge.

BARRETT, P. M. 2009. A new basal sauropodomorph dinosaur from the Upper Elliot Formation (Lower Jurassic) of South Africa. Journal of Vertebrate Paleontology, 29(4), 1032-1045. 
BARRETT, P. M. and UPCHURCH, P. 2007. The evolution of feeding mechanisms in early sauropodomorph dinosaurs. Special Papers in Palaeontology, 77, 91112.

BATES, K. T., MANNION, P. D., FALKINGHAM, P. L., BRUSATTE, S. L., HUTCHINSON, J. R., OTERO, A., SELLERS, W. I., SULLIVAN, C, STEVENS, K. A. and ALLEN V. 2016. Temporal and phylogenetic evolution of the sauropod dinosaur body plan. Royal Society Open Science 3, 15063

BELLAIRS, A. A. and KAMAL, A. M. 1981. The chondrocranium and the development of the skull in recent reptiles. 1-263. In Gans, C. (ed). Biology of the Reptilia. vol. 11, Morphology F. Academic Press, New York.

BENSON, R. B. J., CAMPIONE, N. E., CARRANO, M. T., MANNION, P. D., SULLIVAN, C., UPCHURCH, P. and EVANS, D. C. 2014. Rates of Dinosaur Body Mass Evolution Indicate 170 Million Years of Sustained Ecological Innovation on the Avian Stem Lineage. PLoS Biology, 12(5), e1001853.

BENSON, R. B. J., HUNT, G., CARRANO, M. T. and CAMPIONE, N. 2017. Cope's rule and the adaptive landscape of dinosaur body size evolution. Palaeontology. doi:10.1111/pala.12329

BONNAN, M. F. and YATES, A. M. 2007. A new description of the forelimb of the basal sauropodomorph Melanorosaurus: implications for the evolution of 
pronation, manus shape and quadrupedalism in sauropod dinosaurs. Special Papers in Palaeontology, 77, 157-168

BRONZATI, M. and RAUHUT, O. W. M. 2017. Braincase redescription of Efraasia minor Huene, 1908 (Dinosauria: Sauropodomorpha) from the Late Triassic of Germany, with comments on the evolution of the sauropodomorph braincase. Zoological Journal of the Linnean Society. zlx029.

BRONZATI, M., BENSON, R. B. J. and RAUHUT, O. W. M. 2017b. Data from: Rapid transformation in the braincase of sauropod dinosaurs: integrated evolution of the braincase and neck in early sauropods? Dryad Digital Repository. http://datadryad.org/review?doi=doi:10.5061/dryad.6j336

BRONZATI, M., RAUHUT, O. W. M., BITTENCOURT, J. S. and LANGER, M. C. 2017b. Endocast of the Late Triassic (Carnian) dinosaur Saturnalia tupiniquim: implications for the evolution of brain tissue in Sauropodomorpha. Scientific Reports, 7, 11931.

BUTTON, D. J., RAYFIELD, E. R. and BARRETT, P. M. 2014. Cranial biomechanics underpins high sauropod diversity in resource-poor environments. Proceedings of the Royal Society B, 281, 20142114.

BUTTON, D. J., BARRETT, P. M. and RAYFIELD, E. J. 2016. Comparative cranial myology and biomechanics of Plateosaurus and Camarasaurus and evolution of the sauropod feeding apparatus. Palaeontology, 59(6), 887-913. 
CABREIRA, S. F., KELLNER, A. W. A., DIAS-DA-SILVA, S., SILVA, L. R., BRONZATI, M., MARSOLA, J. C. A., MÜLLER, R. T., BITTENCOURT, J. S., BATISTA, B. J., RAUGUST, T., CARRILHO, R., BRODT, A. and LANGER, M. C. 2016. A unique Late Triassic dinosauromorph assemblage reveals dinosaur ancestral anatomy and diet. Current Biology, 26(22), 3090-3095.

CARBAllido, J. L., POL, D., OTERO, A., CERDA, I. A., SAlGADO, L., GARRIDO, A. C., RAMEZANI, J., CU ENO, N. R. and KRAUSSE, J. M. 2017. A new giant titanosaur sheds light on body mass evolution among sauropod dinosaurs. Proceedings of the Royal Society B, 284, 20171219.

CHATTERJEE, S. and ZHENG, Z. 2002. Cranial anatomy of Shunosaurus, a basal sauropod dinosaur from the Middle Jurassic of China. Zoological Journal of the Linnean Society, 136, 145-169.

CLACK, J. A. and ALLIN, E. 2004. The Evolution of Single- and Multiple-Ossicle Ear in Fishes and Tetrapods. 128-163. In Manley, G. A., Popper, A. N. and Fay, R. R. (eds.). Evolution of the Vertebrate Auditory System. Springer, New York.

CLACK, J. A., FAY, R. R. and POPPER, A. N. 2016. Evolution of the Vertebrate Ear: Evidence from the fossil record. Springer International Publishing, New York, $355 \mathrm{pp}$. 
CLARKE, A. H. 2005. On the vestibular labyrinth of Brachiosaurus brancai. Journal of Vestibular Research, 15(2), 65-71.

CORIA, R. R. and CURRIE, P. J. 2002. The braincase of Giganotosaurus carolinii (Dinosauria: Theropoda) from the Upper Cretaceous of Argentina. Journal of Vertebrate Palaeontology, 22(4), 802-811.

FERREIRA-CARDOSO, S., ARAÚJO, R., MARTINS, N. E., MARTINS, G. G., WALSH, S., MARTINS, R. M. S., KARDJILOV, M., HILGER, A. and CASTANHINHA, R. 2017. Floccular fossa size is not a reliable proxy of ecology and behaviour in vertebrates. Scientific Reports, 7, 2005.

GALTON, P. M. 1985. Cranial anatomy of the prosauropod dinosaur Plateosaurus from the Knollenmergel (Middle Keuper, Upper Triassic) of Germany. II. All the cranial material and details of soft-part anatomy. Geologica et Palaeontologica, 19, 119-159.

GALTON, P.M. and UPCHURCH P. 2004. Prosauropoda. 232-258. In Weishampel, D. B., Dodson, P. and Osmólska, H. (eds.). The Dinosauria, second edition. University of California Press, Berkeley.

GALTON, P. M. and KNOLL, F. 2006. A saurischian dinosaur braincase from the Middle Jurassic (Bathonian) near Oxford, England: from the theropod Megalosaurus or the sauropod Cetiosaurus? Geological Magazine, 143, 905921. 
GOLOBOFF, P. A., FARRIS, J. S. and NIXON KC. 2008. TNT, a free program for phylogenetic analysis. Cladistics, 24, 1-13.

GOLOBOFF, P. A. and SZUMIK, C. A. 2015. Identifying unstable taxa: Efficient implementation of triplet-based measures of stability, and comparison with Phyutility and RogueNaRok. Molecular Phylogeny and Evolution, 88, 93-104.

GOW, C. E. 1975. The morphology and relationships of Youngina capensis Broom and Prolacerta broomi Parrington. Palaeontologia Africana, 18, 89-131.

GOW, C. E. 1990. Morphology and growth of the Massospondylus braincase (Dinosauria, Prosauropoda). Paleontologia Africana, 27, 59-75.

GOWER DJ. 2002. Braincase evolution in suchian archosaurs (Reptilia: Diapsida): evidence from the rauisuchian Batrachotomus kupferzellensis. Zoological Journal of the Linnean Society, 136, 49-76.

GOWER, D. J. and SENNIKOV, A. G. 1996. Morphology and phylogenetic informativeness of early archosaur braincases. Palaeontology, 39(4), 883-906.

GOWER, D. J and WEBER, E. 1998. The braincase of Euparkeria, and the evolutionary relationships of avialans and crocodilians. Biological Reviews, 73, $367-411$. 
HOPSON, J. A. 1980. Relative brain size in dinosaurs: implications for dinosaurian endothermy. 287-210. In Thomas, R. D. K. and Olson, E. C. (eds.). A cold look at the warm blooded dinosaurs. American Association for the Advancement of Science, Washington, DC.

HUENE, F. VON. 1906. Ueber das Hinterhaupt von Megalosaurus bucklandi aus Stonesfield. Neues Jahrbuch fuer Mineralogie, Geologie und Palaeontologie, 1906, $1-12$.

JANENSCH, W. 1935. Die Schädel der Sauropoden Brachiosaurus, Barosaurus und Dicraeosaurus aus den Tendaguru-Schichten Deutsch-Ostafrikas. Palaeontographica Supplement 7, 1(2),147-298.

KNOLL, F. and SCHWARZ-WINGS, D. 2009. Palaeoneuroanatomy of Brachiosaurus. Annales de Paléontologie, 95, 165-175.

KNOLL, F., WITMER, L. M., ORTEGA, F., RIDGELY, R. C. and SCHWARZWINGS, D. 2012. The braincase of the basal Sauropod dinosaur Spinophorosaurus and 3D reconstructions of the cranial endocast and inner ear. PlosOne, 7(1), e30060.

LANGER, M. C., EZCURRA, M. D., BITTENCOURT, J. S. and NOVAS, F. E. 2010. The origin and early evolution of dinosaurs. Biological Reviews, 85: 55110. 
LAURIN , M. 2004. The evolution of body size, Cope's rule and the origin of amniotes. Systematic Biology, 53, 594-622.

LLOYD, G. T. 2016. Estimating morphological diversity and tempo with discrete character-taxon matrices: implementation, challenges, progress, and future directions. Biological Journals of the Linnean Society, 118(1), 131-151.

LLOYD, G. T., BAPST, D. W., FRIEDMAN, M. and DAVIS, K. E. 2016.

Probabilistic divergence time estimation without branch lengths: dating the origins of dinosaurs, avian flight and crown birds. Biology Letters, 12, 20160609.

MANNION, P. D., UPCHURCH, P., CARRANO, M. T. and BARRETT, P. M. 2011. Testing the effect of the rock record on diversity: a multidisciplinary approach to elucidating the generic richness of sauropodomorph dinosaurs through time. Biological Reviews, 86, 157-181.

MARTIN, J. 1987. Mobility and feeding of Cetiosaurus (Saurischia, Sauropoda)why the long neck? 150-155. In Currie, P. M., Koster, E. H (eds). Fourth Symposium on Mesozoic Terrestrial Ecosystems, Short Papers: Occasional Papers of the Tyrell Museum of Palaeontology. Boxtree Books, Drumheller.

MAZZETTA, G. M., CHRISTIANSSEN, P. and FARINA, R. A. 2004. Giants and bizarres: body size of some Southern American Cretaceous dinosaurs. Historical Biology, 16, 1-13. 
MCPHEE, B. W., YATES, A. M., CHOINIERE, J. N. and ABDALA, F. 2014. The complete anatomy and phylogenetic relationships of Antetonitrus longiceps (Sauropodiformes, Dinosauria): implications for the origins of Sauropoda. Zoological Journal of the Linnean Society. 171, 151-205.

MCPHEE, B. W., BONNAN, M. F., YATES, A. M., NEVELING, J. and CHOINIERE, J. N. 2015. A new basal sauropod from the pre-Toarcian Jurassic of South Africa: evidence of niche-partitioning at the sauropodomorph-sauropod boundary? Scientific Reports, 5, 13224.

NAIR, J. P., YATES, A. M., BRONZATI, M., WEISBECKER, V., SALISBURY, S. W. 2015. A new braincase of the near-sauropod dinosaur Melanorosaurus (Late Triassic, Southern Africa), and its systematic and phylogenetic implications. In: Yates AM, ed. CAVEPS Museum of Central Australia, Alice Springs 2015, 15th Conference on Australasian Vertebrate Evolution, Palaeontology and Systematics, 1st September - 5th September 2015: Museum of Central Australia. 41-42.

OTERO, A., KRUPANDAN, E., POL, D., CHINSAMY, A. and CHOINIERE, J. 2015. A new basal sauropodiform from South Africa and the phylogenetic relationships of basal sauropodomorphs. Zoological Journal of the Linnean Society, 174 (3), 589-634. 
OUYANG, H. and YE, Y. 2002. The First Mamenchisaurian Skeleton with Complete Skull, Mamenchisaurus youngi. Sichuan Publishing House of Science and Technology, Chengdu, 111 pp. [in Chinese with English summary]

OWEN, R. 1841. A description of a portion of the skeleton of the Cetiosaurus, a gigantic extinct saurian reptile occurring in the oolitic formations of different portions of England. Proceedings of the Geological Society of London, 3, 457462.

PALMER, T. J. 1979. The Hampen Marly and White Limestone formations: Florida type carbonate lagoons in the Jurassic of central England. Palaeontology, 22, $189-228$.

PAULINA-CARABAJAL, A. 2012. Neuroanatomy of titanosaurid dinosaurs from the Upper Cretaceous of Patagonia, with comments on endocranial variability within Sauropoda. Anatomical Record, 295(12), 2141-2156.

PAULINA-CARABAJAL, A., CARBALLIDO, J. L. and CURRIE, P. J. 2014. Braincase, neuroanatomy and neck posture of Amargasaurus cazaui (Sauropoda: Dicraeosauridae) and its implications for understanding head posture in sauropods. Journal of Vertebrate Paleontology, 34, 870-882.

PEYRE de FABRÈGUES, C., ALLAIN, R. and BARRIEL, V. 2015. Root causes of phylogenetic incongruence observed within basal sauropodomorph interrelationships. Zoological Journal of the Linnean Society, 175(3), 569-586. 
POL, D., GARRIDO, A. and CERDA, I. A. 2011. A new sauropodomorh dinosaur from the Early Jurassic of Patagonia and the origin and evolution of the Sauropod-type sacrum. Plos ONE, 6(1), e14572.

POL, D. and POWELL, J. E. 2007. New information on Lessemsaurus sauropoides (Dinosauria: Sauropodomorpha) from the Upper Triassic of Argentina. Special Papers in Palaeontology, 77, 223-243.

PRIETO-MÁRQUEZ, A. and NORELL, M. A. 2011. Redescription of a nearly complete skull of Plateosaurus (Dinosauria: Sauropodomorpha) from the Late Triassic of Trossingen (Germany). American Museum Novitates, 3727, 1-58.

RAUHUT, O. W. M. 2007. The myth of the conservative character: braincase characters in theropod phylogenies. Hallesches Jahrbuch für Geowissenschaften, Beiheft, 23, 51-54

RAUHUT, O. W. M., FECHNER, R., REMES K, REIS, K. 2011. 119-149. How to get big in the Mesozoic: the evolution of the sauropodomorph body plan. In: (eds. Klein N, Remes K, Gee CT, Sander PM). Biology of the sauropod dinosaurs: understanding the life of giants. Bloomington and Indianapolis: Indiana University Press.

ROMER, A. S. 1956. Osteology of the Reptiles. University of Chicago Press, Chicago, $772 \mathrm{pp}$. 
SALGADO, L., CORIA, R. A. and CALVO, J. O. 1997. Evolution of titanosaurid sauropods. I. Phylogenetic analysis based on the postcranial evidence. Ameghiniana, 34, 3-32.

SAMPSON, S. D. and WITMER, L. M. 2007. Craniofacial anatomy of Majungasaurus crenatissimus (Theropoda: Abelisauridae) from the Late Cretaceous of Madagascar. Journal of Vertebrate Paleontology, 27, 32-102.

SANDER, P. M. 2013. An Evolutionary Cascade Model for Sauropod Dinosaur Gigantism - Overview, Update and Tests. PLoS ONE, 8(10), e78573.

SANDER, P. M., CHRISTIAN, A., CLAUSS, M., FECHNER, R., GEE, C. T., GRIEBELER, E. -M., GUNGA, H. -C., HUMMEL, J., MALLISON, H., PERRY, S. F., PREUSCHOFT, H., RAUHUT, O. W. M., REMES, K., TÜTKEN, T., WINGS, O. and WITZEL, U. 2011. Biology of the sauropod dinosaurs: the evolution of gigantism. Biological Reviews, 86, 117-155.

SERENO, P. C. 1999. The evolution of dinosaurs. Science, 284, 2137-2147.

SERENO, P. C., BECK, A. L., DUTHEIL, D. B., LARSSON, H. C. E., LYON, G. H., MOUSSA, B., SADLEIR, R. W., SIDOR, C. A., VARRICCHIO, D. J., WILSON, G. P. and WILSON, J. A. 1999. Cretaceous sauropods from the Sahara and the uneven rates of skeletal evolution among dinosaurs. Science, 286, 13421347. 
SERENO, P. C., WILSON, J. A., WITMER, L. M., WHITLOCK, J. A., MAGA, A., IDE. O. and ROWE, T. 2007 Structural extremes in a Cretaceous dinosaur. PLoS One, 2, e1230.

SERENO, P. C., MARTINEZ, R. N. and ALCOBER, O. A. 2012. Osteology of Eoraptor lunensis (Dinosauria, Sauropodomorpha). Journal of Vertebrate Paleontology, 32(suppl. 6), 83-179.

SNIVELY, E. and RUSSELL, A. P. 2007. Functional morphology of neck musculature in the Tyrannosauridae (Dinosauria, Theropoda) as determined via a hierarchical inferential approach. Zoological Journal of the Linnean Society, 151, 759-808.

SOBRAL, G., HIPSLEY, C. A. and MÜLLER, J. 2012. Braincase redescription of Dysalotosaurus lettowvorbecki (Dinosauria, Ornithopoda) based on computed tomography. Journal of Vertebrate Paleontology, 32, 1090-1102.

THOMSON, K. S. 1988. Morphogenesis and evolution. Oxford University Press, Oxford, $154 \mathrm{pp}$.

TSCHOPP, E., MATEUS, O. and BENSON, R. B. J. 2015. A specimen-level phylogenetic analysis and taxonomic revision of Diplodocidae (Dinosauria, Sauropoda). PeerJ, 3, e857. 
UPCHURCH, P., BARRETT, P.M. and DODSON, P. 2004. 259-322. Sauropoda. In Weishampel, D.B., Dodson, P., and Osmolska, H. (eds). The Dinosauria (2nd Edition). University of California Press, Berkeley.

UPCHURCH, P., BARRETT, P. M. and GALTON, P. M. 2007. A phylogenetic analysis of basal sauropodomorph relationships: implications for the origin of sauropod dinosaurs. Special Papers in Palaeontology, 77, 57-90.

WEDEL, M. J. 2005. Postcranial skeletal pneumaticity in sauropods and its implications for mass estimates. 201-228. In Curry Rogers, K. A. and Wilson, J. A. (eds). The Sauropods: Evolution and Paleobiology. University of California Press, Berkeley.

WEDEL, M. J. 2007. What pneumaticity tells us about 'Prosauropods', and vice versa. Special papers in Palaeontology, 77, 207-222.

WEDEL, M. J. and SANDERS, R. K. 2002. Osteological correlates of cervical musculature in Aves and Sauropoda (Dinosauria: Saurischia), with comments on the cervical ribs of Apatosaurus. PaleoBios, 22(3), 1-6.

WEDEL, M. J., CIFELLI, R. L. and SANDERS, R. K. 2000. Osteology, paleobiology, and relationships of the sauropod dinosaur Sauroposeidon. Acta Palaeontologica Polonica, 45, 343-388 
WILLS, M. A., BRIGGS, D. E. G. and FORTEY R. A. 1994. Disparity as an evolutionary index: a comparison of Cambrian and Recent arthropods. Paleobiology, 20, 93-130.

WILSON, J. A. 2005. Overview of sauropod phylogeny and evolution. 15-49. In Curry Rogers, K. A. and Wilson, J. A. (eds). The Sauropods: Evolution and Paleobiology. University of California Press, Berkeley.

WITMER, L. M., CHATERJEE, S., FRANZOSA, J. and ROWE T. 2003. Neuroanatomy of flying reptiles and implications for flight, posture and behaviour. Nature, 425, 950-953.

WITMER, L. M., RIDGELY, R. C., DUFEAU, D. L. and SEMONES, M. C. 2008. Using CT to peer into the past: 3D visualization of the brain and ear regions of birds, crocodiles, and nonavian dinosaurs. 67-87 In Endo, H. and Frey, R. (eds). Anatomical imaging: towards a new morphology. Springer-Verlag, Tokyo.

WITZEL, U. and PREUSCHOFT, H. 2005. Finite-element model construction for the virtual synthesis of the skulls in vertebrates: case study of Diplodocus. Anatomical Record, 283, 391-401.

WYATT, R. J. 1997. A correlation of the Bathonian (Middle Jurassic) succession between Bath and Burford, and its relation to that near Oxford. Proceedings of the Geologists' Association. 107, 299-322. 
YATES, A. M. 2007a. Solving a dinosaurian puzzle: the identity of Aliwalia rex Galton. Historical Biology, 1, 93-123.

YATES, A. M. 2007b. The first complete skull of the Triassic dinosaur Melanorosaurus Haughton (Sauropodomorpha: Anchisauria). Special Papers in Palaeontology, 77, 9-55.

YATES, A. M., BONNAN, M. F., NEVELLING, J., CHINSAMY, A. and BLACKBEARD, M. G. 2010. A new transitional sauropodomorph dinosaur from the Early Jurassic of South Africa and the evolution of sauropod feeding and quadrupedalism. Proceedings of the Royal Society of London B, 277(1682), 787794.

ZHANG, Y. 1988. The Middle Jurassic Dinosaur Fauna from Dashanpu, Zigong, Sichuan: Sauropod Dinosaurs. Vol. 1, Shunosaurus. Sichuan Publishing House of Science and Technology, Chengdu, 88 pp. [in Chinese with English summary]

\section{DATA ARCHIVING STATEMENT}

Data for this study are available in the Dryad Digital Repository: http://datadryad.org/review?doi=doi:10.5061/dryad.6j336 (Data of phylogenetic and rates of evolution analyses); and in the MorphoSource Repository: http://morphosource.org (CT Scan data and media files).

\section{Figures Captions}


Figure 1: Braincase of the specimen OUMNH J13596 (i.e. 'Oxford Braincase' in this study) in left lateral (A), dorsal (B), and posterior (C) views, and cranial endocast of the specimen OUMNH J13596 in left lateral (D), dorsal (E), and ventral (F) views. Abbreviations: ASC - anterior semicircular canal; fl - floccular fossa lobe of the cerebellum; fm - foramen magnum; fo - fenestra ovalis; la - lagena; 1s laterosphenoid; LSC - lateral semicircular canal; mevd - dorsal ramus of the midcerebral vein; $\mathrm{mcvv}$ - ventral ramus of the mid-cerebral vein; $\mathrm{mf}$ - metotic foramen; ot - otoccipital; pa - parietal; pbs - parabasisphenoid; po - prootic; pp - paroccipital process; PSC - posterior semicircular canal; sin - dural sinus; snc - sagittal nuchal crest of the supraoccipital; so - supraoccipital; stf - supratemporal fenestra; V trigeminal nerve; VI - abducens nerve; VII - facial nerve; IX - glossopharyngeal nerve; X - vagus nerve; XI - accessory nerve; XII - hypoglossal nerve.

Figure 2: Reduced strict consensus tree of the phylogenetic analysis calibrated against geological time, and moments of the activation of the 'neck and head' cascade. Taxa with the name written in black correspond to those included in the discrete character-taxon matrices analyses. Silhouettes indicate the average body plan of unnamed sauropodomorph subgroups matching the horizontal bar. The star indicates the branch for which a high rate of evolution was detected in the analysis. Abbreviations: BM - body mass.

Figure 3: Results of the principal coordinate analysis with the variation in PCo 1 plotted against PCo2. Circles identify non-sauropodan sauropodomorphs, squares identify sauropods, and pentagons identify other archosaurs. 


\section{Table Caption}

Table 1: Relative cranial/femoral length and relative neck/trunk length of distinct sauropodomorph dinosaurs. 

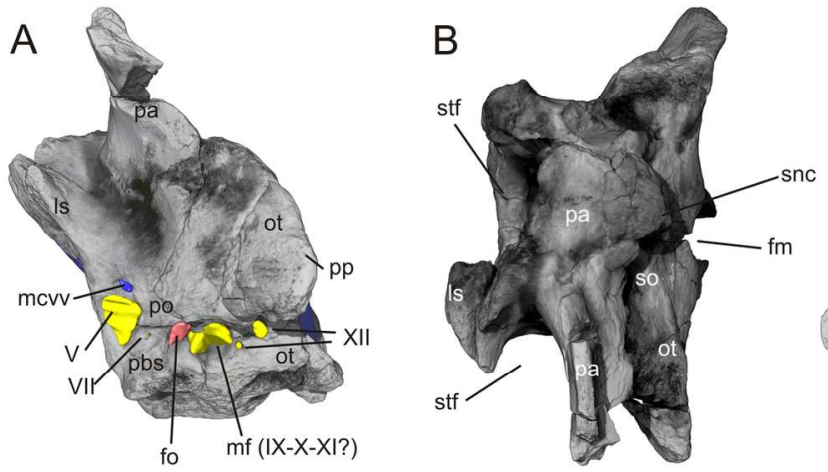

C
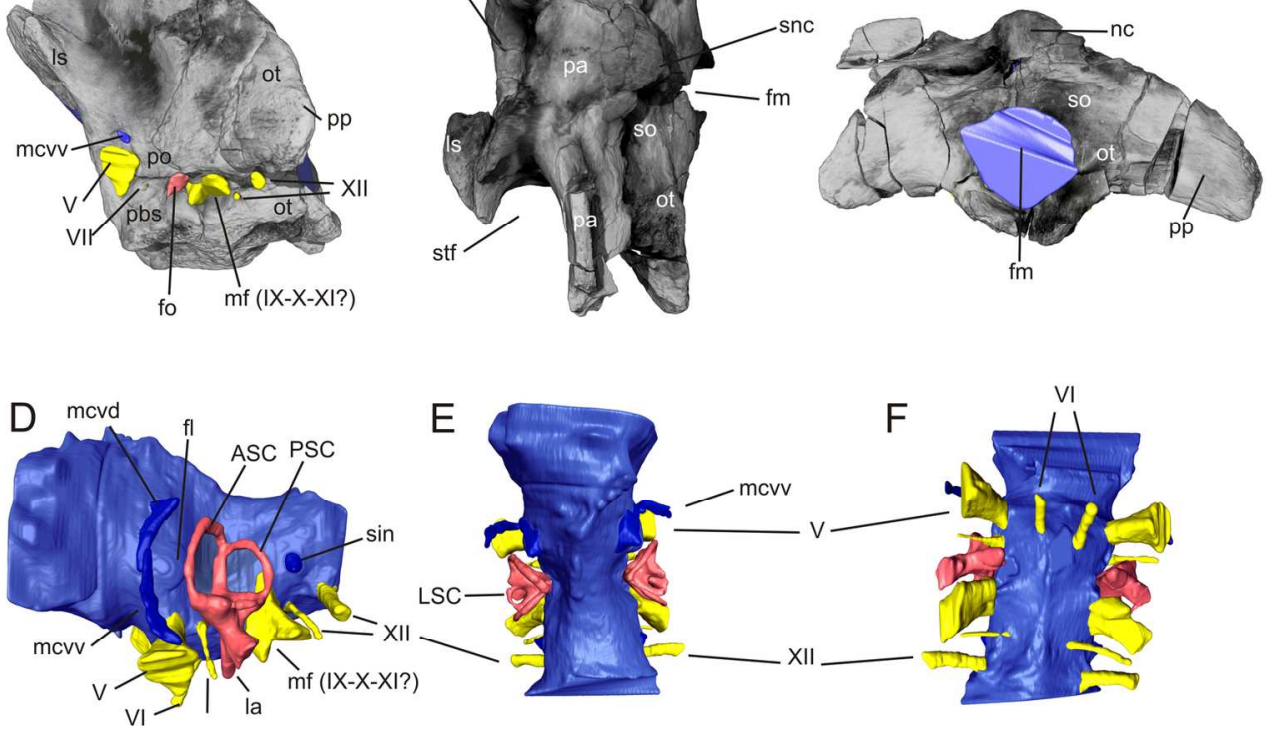

Figure 1: Braincase of the specimen OUMNH 13596 (i.e. 'Oxford Braincase' in this study) in left lateral (A), dorsal (B), and posterior (C) views, and cranial endocast of the specimen OUMNH J13596 in left lateral (D), dorsal (E), and ventral (F) views. Abbreviations: ASC - anterior semicircular canal; fl - floccular fossa lobe of the cerebellum; fm - foramen magnum; fo - fenestra ovalis; la - lagena; Is - laterosphenoid; LSC lateral semicircular canal; mcvd - dorsal ramus of the mid-cerebral vein; mcvv - ventral ramus of the midcerebral vein; mf - metotic foramen; ot - otoccipital; pa - parietal; pbs - parabasisphenoid; po - prootic; pp - paroccipital process; PSC - posterior semicircular canal; sin - dural sinus; snc - sagittal nuchal crest of the supraoccipital; so - supraoccipital; stf - supratemporal fenestra; V - trigeminal nerve; VI - abducens nerve; VII - facial nerve; IX - glossopharyngeal nerve; X - vagus nerve; XI - accessory nerve; XII hypoglossal nerve.

$151 \times 112 \mathrm{~mm}(300 \times 300 \mathrm{DPI})$ 


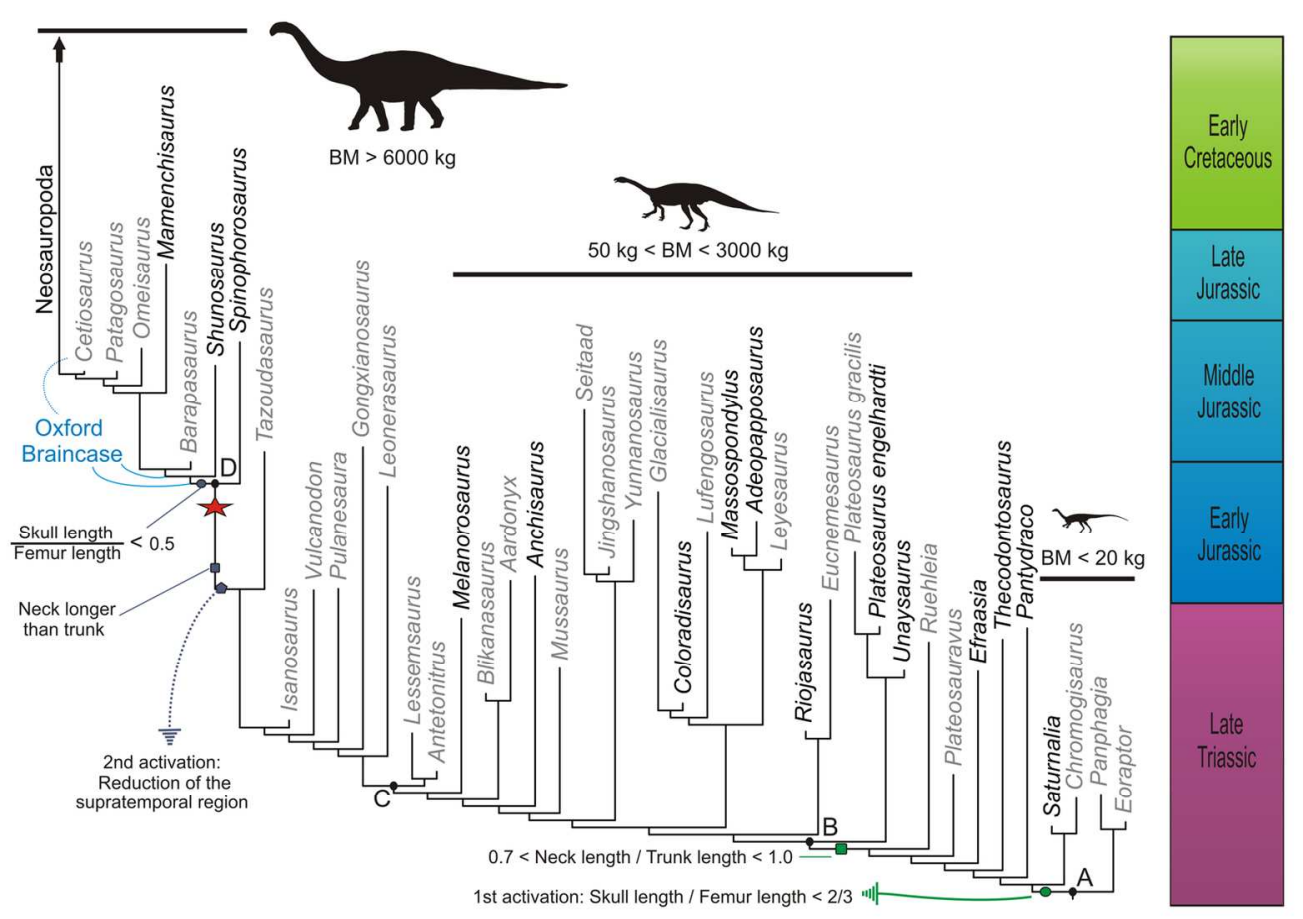

Figure 2: Reduced strict consensus tree of the phylogenetic analysis calibrated against geological time, and moments of the activation of the 'neck and head' cascade. Taxa with the name written in black correspond to those included in the discrete character-taxon matrices analyses. Silhouettes indicate the average body plan of unnamed sauropodomorph subgroups matching the horizontal bar. The star indicates the branch for which a high rate of evolution was detected in the analysis. Abbreviations: BM - body mass.

$$
141 \times 99 \mathrm{~mm}(300 \times 300 \mathrm{DPI})
$$




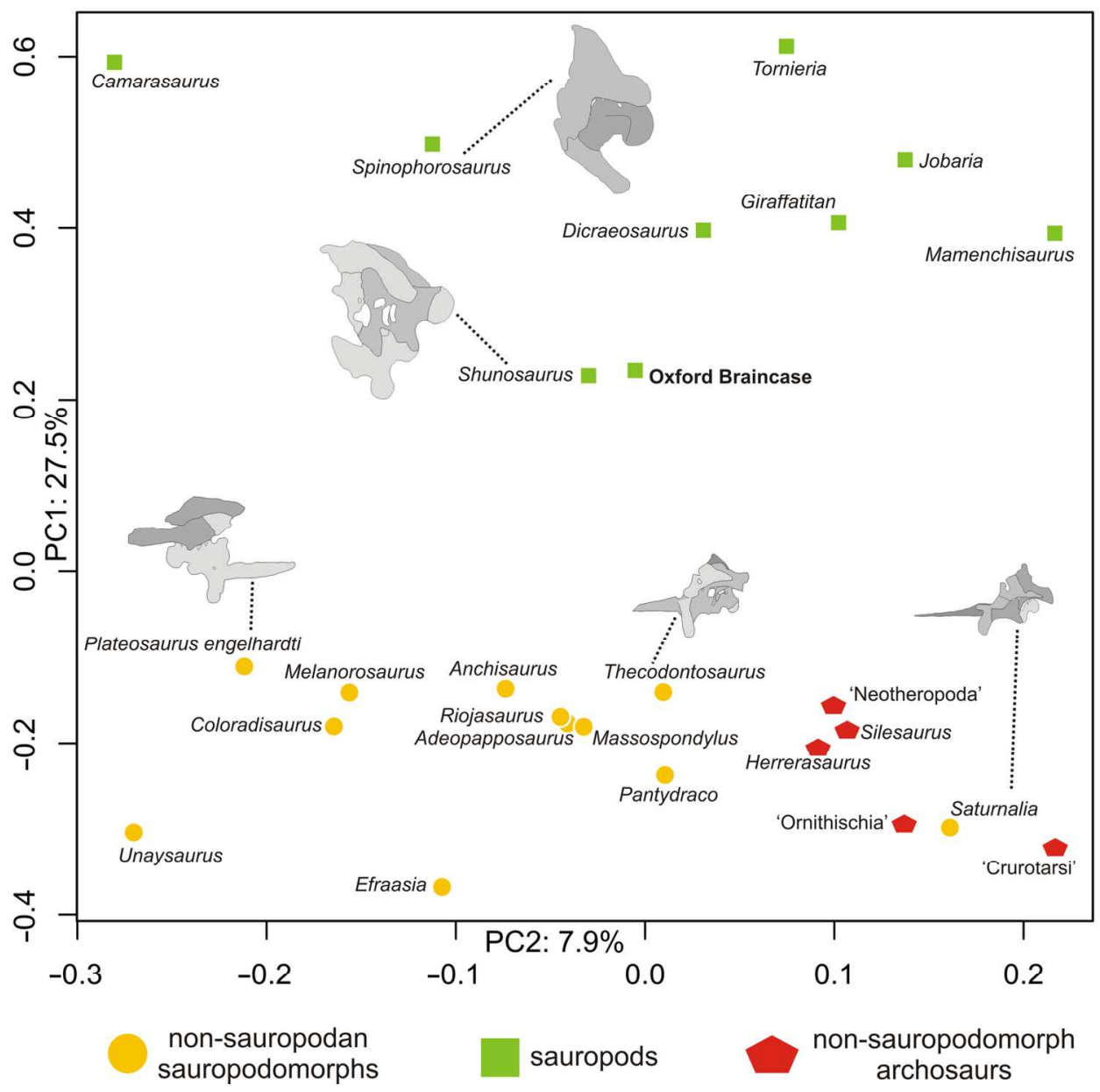

Figure 3: Results of the principal coordinate analysis with the variation in PCo 1 plotted against PCo2. Circles identify non-sauropodan sauropodomorphs, squares identify sauropods, and pentagons identify other archosaurs.

$$
139 \times 136 \mathrm{~mm}(300 \times 300 \mathrm{DPI})
$$




\begin{tabular}{l|r}
\multicolumn{1}{c}{ Taxon (specimen number) } & Cranial length / Fem \\
\hline Eoraptor lunensis (PVSJ 512) & 0.81 \\
Saturnalia tupiniquim (MCP 3845PV) & 0.6 \\
Plateosaurus engelhardti (GPIT 1; SMNS 13200) & 0.57 \\
Melanorosaurus readi (NM QR3314) & 0.53 \\
Shunosaurus lii (ZDM T 5402) & 0.35 \\
Mamenchisaurus youngi (ZDM 0083) & 0.44 \\
Camarasaurus sp. (CM 11338) & 0.22
\end{tabular}


1

2

3

4

5

6

7

8

9

10

11

12

13

14

15

16

17

18

19

20

21

22

23

24

25

26

27

28

29

30

31

32

33

34

35

36

37

38

39

40

41

42

43

44

45

46

47

48

49

50

51

52

53

54

55

56

57

58

59

60
Neck length / Trunk length

$0,50-0,55$
$0,55-0,60$
$0,75-0,79$
$?$
1.18
3.22
1.07

$0,50-0,55$

$0,55-0,60$

322

1.07

\section{Reference}

Bronzati et al. 2017

Bronzati et al. 2017

Rauhut et al. 2011

Yates, 2007b

Rauhut et al. 2011

Rauhut et al. 2011

Rauhut et al. 2011 